\title{
Patterns of Cultural Inclusion and Exclusion in American Society: The Case of Chaldean Americans
}

\author{
Lanouar Ben Hafsa ${ }^{1}$ \\ ${ }^{1}$ University of Tunis, Faculty of Human and Social Sciences, Tunisia \\ Correspondence: Lanouar Ben Hafsa, University of Tunis, Faculty of Human and Social Sciences, Tunisia.
}

Received: June 11, 2018

doi:10.11114/ijsss.v6i8.3475
Accepted: July 3, 2018 Available online: July 24, 2018

URL: https://doi.org/10.11114/ijsss.v6i8.3475

\begin{abstract}
This study aims to shed light on a community for long positioned as Arab and/or Muslim but still in search of a sense of belonging that promotes its ancestral heritage and at the same time reinforces bonds of solidarity among its members. It investigates the rhetoric around the Detroit-based Chaldean diaspora, not merely as case in point, but also because this is where the bulk of Chaldean Americans are concentrated. While it retraces their pathway from the homeland (Iraq) up through their establishment in the United States, it essentially explores the debate surrounding the group's identity formation. Principally, it seeks to scrutinize patterns of continuity and change operating within the Chaldean microcosm, namely to demonstrate that the construct "ethnic identity" is more than a question of self-perception. It rather involves an interplay of mechanisms that concur to preserve the group's distinctive features and keep it shielded against threatening erasure. The investigation suggests to evidence, ultimately, that even though it exhibits broad consensus on basic elements of association that unify its individual members, notably Church and family, the Chaldean diaspora is by no means conflict-ridden. In effect, the persevering influx of co-ethnics fleeing persecution in the homeland appears to be a new source of internal frictions likely to polarize the community and precipitate an identity crisis.
\end{abstract}

Keywords: Chaldean Americans, ethnic identity, assimilation, internal frictions

\section{Introduction}

The concept "ethnic identity" is not a recent one. In the United States, better known for its ethno-religious diversity, it even preceded the great migration of the late $19^{\text {th }}$ and 20th centuries, and had rather been used in reference to racial identity. Even though unavoidable in forums pertaining to assimilation and the melting pot in general, the construct started to reemerge in social behavioral sciences literature in the 1960s and 1970s, when ethnic minority groups began to claim civil rights up to then denied to them (Bell, 1975: 174).

However, the concept is too far from generating consensus among ethnic theorists who still fall short of setting on a common definition to the designate in question. If a significant number among them appear to converge on the assumption that ethnic identity formation is by no means a static process (Phinney, 2003: 63), but rather a dynamic and fluid one, others suggest that it has become nothing more than a cliché term, more and more difficult to elucidate (Gleason, 1996).

The study gauges to probe the rhetoric surrounding the Chaldean American community, especially to explore the dynamics of a group, erroneously positioned as Arab/Muslim, but still in search of a sense of identity that promotes ancestral ties and at the same time binds community members together in a multicultural environment. It aims to spotlight a group that traces its origin to present day Iraq, but that largely takes pride neither in its national origin, nor in the Arabic language spoken by the majority of their former fellow citizens. It seeks to demonstrate how, despite its adherence to American values and symbols, the community steadfastly refuses to relinquish its own cultural and linguistic heritage which it endeavors to pass over to future generations.

To date, very little has been written about the American-based Chaldean diaspora. Understandably, due to its tiny size, the group has either been completely ignored by social scientists, or at best has not been sufficiently addressed in ethnic literature, written in larger part by non-Chaldeans. Actually, except for several references, notably the authoritative book, The Chaldean-Americans: Changing Conceptions of Ethnic Identity, by renowned sociologist Mary C. Sensgstock, few material has been published about the group that, otherwise, would have helped bring the community to more visibility. 
A number of factors have motivated this research. In addition to bringing to the surface one of the least studied and least known ethnic groups in the United States, the study is meant to explore the myth around a closely-knit community that outstandingly has known how to perpetuate its cultural legacy across the different generations, especially how to preserve its oneness in multiethnic contexts.

Another rationale for such an investigation is the group's singularity in terms of identity construction, as the process of building and sustaining well-entrenched bonds of ethnic solidarity among its fellow members is by no means a recent phenomenon, but had rather started long before their arrival and settlement in the host country.

Lastly, we have chosen to confine the scope of the research to the larger Detroit area (MI), not simply to take the local Chaldeans as a case in point, but just because this is where a majority among the group members are clustered. Overall, as asserted by well-known sociologist Andrew Greeley, "Small groups like the Chaldeans are interesting, not only in themselves... but also and especially because they are excellent laboratories for studying up close mechanisms of identity formation and preservation which seem to operate among large groups too." (Sengstock, 1982: Preface)

The study utilizes a hybrid approach involving both qualitative and quantitative research methods. It centers around three major axes and is correspondingly subdivided into three main sections:

Section 1 provides a general overview of the group. It retraces their pathway from the homeland up through their establishment in the host country. It details their demographic evolution since their arrival, depicts their socio-economic profile, and highlights patterns of interaction within the community, especially the vital role played by three major institutions: Church, family, and ethnic occupation, in consolidating bonds of group solidarity alongside spatiotemporal lines.

Section 2 explores the rhetoric surrounding the group's identity formation. It scrutinizes the various patterns of continuity and change operating in the Chaldean microcosm, and the way they have continually refashioned their sense of belonging and sustained group survival. Essentially, it seeks to capture the manner in which the community interacts with forces outside its ethnic confines, more specifically to demonstrate that the construct "ethnic identity" is more than a question of self-perception. It extends far beyond the boundaries of the ethnic enclave as it involves, rather, an interplay of factors likely to generate more confusion and misinterpretations.

Section 3, eventually, elaborates further on the question of ethnic construction which it situates in the lineage of other groups that went through the same process of self-identification, and that ultimately reached group cohesion and group unity. It principally aims to show that while Chaldean Americans can exhibit a high degree of communal strength, notably broad consensus on unifying institutions such as Church and family, they are by no means conflict ridden. The unending influx of co-ethnics fleeing persecution in the homeland appears to be a new source of internal frictions likely to polarize the community and precipitate an identity crisis.

\section{Overall Profile}

\subsection{Immigration}

As is true with other ethnic minorities, the promise of a better living in the land of milk honey started to lure Chaldean immigrants as early as the 1880s. However, not until 1910-1912 did the first significant Chaldean wave occur, with all male, mostly small farmers and laborers arriving from Northern Iraq villages of Telkaif, Alkosh, Araden, and Batnaya (Sengstock, 1982: 42-43). In fact, while it is difficult to determine their exact number, due to non-availability of statistical data concerning the group, it is quite plausible to identify factors behind their departure from the country of origin. Tempted, alongside other immigrants, by Henry Ford's promise of five dollars per day, they chose to settle in the Greater Detroit area, MI, home of the U.S. automobile industry. Thus, in addition to the likelihood of being hired in the flourishing automotive factories, the opportunity to cohabit with an already established and Arab-speaking Lebanese Maronite community in that area had been a decisive pull factor for the first Chaldean stock who came initially as temporary residents. (Przybysz, 2012)

The limited amount of statistical data gathered so far with regard to the Chaldean group relate imprecise, if not contradictory information pertaining to the demographic evolution of such a minority, very often lumped in the Arab category. According to Sengstock, a formal count of the group has been made possible only after the arrival in Detroit of the first Chaldean priest who founded the first Chaldean parish in 1947. He listed eighty families of Chaldean descent living in the area, a number that grew to nearly 200 in 1957, to reach 658 and 3,416 individuals in 1967 (Sengstock, 1982: 43).

Retrospectively, the passage in 1924 of the Immigration Act (or Johnson-Reed Act) imposing a rigid quota system on non-European stocks and reducing the number of Iraqi entries to only 100 per year, did not interrupt the flow of Chaldean arrivals notably from the village of Telkaif. The regular increase of the community size could be explained by what migration theorists dub "chain migration," a pattern quite common Chaldean Americans. Once settled, new 
residents would immediately seek to provide logistical assistance (passage money, accommodation, job opportunities, etc.) to their parents, siblings and friends in the homeland. Alternatively, with the introduction of the student visa after the Second World War, a substantial number of Chaldean entered the United States supposedly for educational reasons, but chose to remain in the host country, thanks to the help of co-ethnics. (Sengstock, 1982: 43)

The 1965 Immigration and Nationality Act marked a turning point in U.S. immigration history. It lifted the quota system and initiated a new influx of Chaldean stock who were pushed by both economic and religious factors, and who were different in many respects from their predecessors. For instance, while most former immigrants trace their origin to the single town of Telkaif, recent arrivals poured from Baghdad and other urban centers where they were born and reared.

The Chaldean population continued to grow exponentially in Metropolitan Detroit subsequent to the U.S. invasion of Iraq in 2003 and the factional conflicts it had sparked across the region. The war, especially the rise of radical Islamist groups, on top of them the infamous ISIS, placed Christian minorities in a strainful situation where they had to either fight or flee the homeland to escape religious persecution. In effect, despite restrictions imposed by the U.S. government on immigration from Iraq (as a consequence of the Gulf War), Chaldean immigrants continued to arrive, this time as political refugees and asylum seekers, on the basis that their area was contested by both Kurdish and Iraqi forces. (Sengstock, 1982: 43)

Today, the Chaldean population in the Detroit area has ballooned to about 150,000, exceeding by far that of their fellow compatriots in Telkaif. Meanwhile, the local population seems to have reached a saturation point and could neither absorb the arriving masses nor respond to their urging needs. Rather, established Chaldeans are now turning to relief associations for help, while simultaneously pressuring federal authorities for a more lenient policy with regard to new Iraqi refugees. (Kamoo, 1999)

\subsection{Socio-Cultural Patterns}

Still unknown to the American public, the Detroit-based Chaldean diaspora exhibits socio-cultural traits that appear singular and worth exploration. Essentially, Chaldean Americans stand for an ideal case to demonstrate how a community can build and sustain a sense of ethnic sameness to preserve and perpetuate its cultural heritage. Accordingly, not only did its members bring with them customs and traditions they inherited from their ancestors, but also longstanding community values, notably an unflinching dedication to Church, tenuous family ties, and a deep imprint of ethnic economic enterprise. Actually, though they may share these characteristics with other ethno-religious communities, notably the Irish and the Italians, failure to deviate from the community ethnic code is by contrast a rare phenomenon.

Chief among the diverse mechanisms cementing internal group ties and promoting consensus and communal strength, is the local Church which, in addition to standing for a unifying symbol, operates as a social center. It especially provides a public space where community members congregate regularly to exchange news and gossip.

By no means and in any way a religious sect, as some tend to believe, the Chaldean Church traces its roots to an early biblical era corresponding to the spread, two thousand years ago, of Christianity in Mesopotamia (present day Iraq). Even though they have different rituals as they practice a rite of Roman Catholicism known as the "Chaldean rite," Chaldeans strongly affirm that they are undistinguishable from their Western coreligionists. Nevertheless, the official establishment of the Chaldean Catholic Church dates back to February 20, 1553, when Pope Julius III proclaimed the Bishop of Mosul "Patriarch of the Chaldeans" (Rabban, 1967: 428).

Protective of their Christian beliefs in the midst of a predominantly Muslim environment, where relations with their Muslim counterparts have variably been tense (Hourani, 1946: 428), Chaldeans take equally pride in speaking the Aramaic language, a language which had been the lingua franca of Mesopotamia, and which they continue to use and refer to as "Jesus's language." Today, due to probably some kind of ethnocentricity and religious zealotry, they appear to be trapped "in the uncomfortable position of being 'too Roman' to please other Eastern Christians and 'not Roman enough' to satisfy most Western Catholics" (Sengstock, 1982: 14).

Interestingly, though they may be isolated as Christians in a strained Muslim context, or marginalized in a largely Latin rite milieu, to Chaldean Americans the Church is an essential rallying focus to which nearly all community members hail for both religious and societal rituals (baptisms, weddings, funerals, etc.). Additionally, the Church provides relief service to the needy among Chaldeans, notably the newly arrived refugees or asylum seekers. As pointed out by Sengstock, "At the ethnic Church, the immigrant finds a setting where his native language, either Chaldean (Aramaic) or Arabic, or both, is known and used, where family and religious customs are familiar; and where the attitudes and ideas are similar to his own. At the same time it is a place where he can get assistance with learning English, hints on starting a business, and help with any number of problems in adjusting to American society" (Sengstock, 1982: 21). Similarly, the Chaldean priest is the one to whom community members turn to for godly or worldly service. He 
becomes "the lawyer to consult regarding immigration problems; the social worker who helps with family problems; and the counselor regarding financial problems" (Sengstock, 1982: 22).

In addition to being ostensibly religious, the American Chaldean community has been pictured as family oriented. Not only the family exerts a great of influence over the group members, but also fulfils a colossal function holding the community together and promoting internal unity (Prothro \& Diab, 1974: 61-62). What's more, Chaldean Americans exhibit a strong sense of kinship rarely encountered in other minority groups. This exceptional feature, according to certain social scientists, extends back to a traditional family structure the Chaldeans brought with them from the homeland, and which was basically patrilineal, extended and endogamous. As a matter of fact, while a number of formerly observed rites (such as strictly arranged marriages) are no longer practiced today in the host country, an outright determination to perpetuate the community's spirit of mutual help still persists among its members who feel bound by ties of "blood and obligation" to provide critical community services, not only to more distant kin (parents, siblings, and other relatives), but also to Chaldean immigrants who continue to arrive unendingly from the country of origin. That meant offering them shelter, and especially a job in the family business, a role fully assumed by what has accurately been termed the "functionally extended family" (Farsoun, 1970: 24). Failure to provide such an assistance would be interpreted as an utter lack of respect toward ancestral customs of generosity and hospitability.

Eventually, frequent and close contacts between the members of the Chaldean family and within the community as a whole are maintained also thanks to entrepreneurial instincts diaspora members succeeded in transmitting across generations. Thus, in addition to the vital role played by Church and family in preserving strong community ties, the ethnic occupation appears to be an efficacious instrument to reinforce bonds of solidarity among members, namely to keep them clustered in the same areas where they can meet and interact frequently (Sengstock, 1974).

\section{The Development of an Ethnic Identity}

Even though they exert a profound influence over the life and behavior of American Chaldeans, Church and family are by no means the sole unifying attributes that bind the group members together. Sharing a common ancestry that extends back to a pre-Christian era, especially preserving a sense of ethnic identity that they vehemently defended across the ages, are considered as crucial factors that continue to nurture the myth around such an atypical community.

The present section delves into the history and evolution of the American Chaldean diaspora. It namely analyzes the process of ethnic identification of a closely-knit group that not only has survived its minority status in ethno-religious homogenizing contexts, but also has succeeded in perpetuating its core identity. What's more, conceiving of themselves as a live continuation of an ancient civilization and the holders of disparate fragments of a common past has variably translated into distancing themselves from the domineering majority by emphasizing their distinct features. All this considered, a number of questions come to the fore: How did Chaldean identity evolve and develop in time and space? What are its constituting elements or facets? How did Chaldeans survive historical challenges and often-overwhelming social mutations to preserve their oneness? In other terms, what survival strategies did they deploy to resist group dislocation in continually changing environments?

\subsection{Chaldeans before Relocation}

To retrace the long and arduous process of Chaldean identity formation and better understand the nomenclature "Chaldean," one should get back to the ancient origins of Chaldean people with roots stretching back to Abraham, the biblical patriarch of Judaism, Christianity and Islam. But Chaldean political history is traced back to the seventh century BC, precisely in 625, when Nabopolassar defeated the Assyrians and became king of the New Babylonian Empire. (Hanish, 2010).

The inauguration of the Chaldean dynasty by no means signaled the end of the Assyrian presence and culture. History books even ascertain that Assyrians and Chaldeans were (and still are) ethnically, culturally, and linguistically the same people, divided only alongside political allegiances. As the ancient inhabitants of Mesopotamia, both groups continued to cohabit on the same territory until the advent of Christianity to which they gradually converted and formed what came to be called the "Church of the East," dropping by the same token their original names and embracing a "Christian identity." (Shathaya, 1999)

The first split between Chaldeans and Assyrians came in $431 \mathrm{AD}$ as a result of a Christological dispute over specific dogmas concerning Christ's personhood (also known as the 431-544 Nestorian Schism), but soon both groups had to reunite to resist disintegration in what was to become later the land of Islam. Actually, the advent of the new faith in the mid- $7^{\text {th }}$ c. not only swept most of Mesopotamia, but also imposed Arabic as the lingua franca of a larger part of the Middle East. (Shathaya, 1999)

Modern history reveals a new story where the descendants of ancient inhabitants of Mesopotamia have to surmount their religious frictions and defend a common linguistic and cultural heritage. However, to overcome threats to their 
survival as a "tiny island of Christianity in a sea of Islam," (Norris, 2006) they need first to surpass their divisive views regarding ethnic identity, and conceive of their Christian faith as a unifying force. For Chaldeans, more specifically, preserving their cultural heritage presupposed perpetuating their Christian faith and their Aramaic language. To this end, the designate "Chaldean" became not only central to their identity construction, but also a highly distinctive feature that differentiated them from their Assyrian counterparts. As asserted by Sengstock: "For Chaldeans, a major basis for out-group formation is religion. Chaldeans have long been a minority group in the Middle East for many reasons, but the religious affiliation is perhaps the most obvious. Being Christian, they stand clearly in contrast to their Moslem neighbors... Even among Middle Eastern Christians the Chaldeans are a minority, for they are in union with the Pope of Rome in contrast to the Nestorians and Orthodox Christians." (1982: 110)

The rise of Arab nationalism in the early twentieth century, coinciding with the waning years of the Ottoman Empire, reinforced among Chaldeans a sense of group solidarity, even if the sweeping movement was plainly secular and in no way stood for an immediate threat to the disparate Christian conclaves across the region. Notwithstanding, to many Iraqi Chaldeans, the labels "Arab" and "Muslim" had become so tightly intertwined and, to certain extents, mutually exclusive that non-identification with the one and/or the other might expose them to further marginalization and predictably amplify the threat of majority persecution. Furthermore, to a sizable segment among them, cohabiting peacefully with their Arab and Muslim peers in a multiethnic and multi-confessional context on no account implied conceding on their specific traits, notably their indefectible dedication to their Church and their ancestral language. What's more, even if they demonstrated measured support for the all-embracing nationalist drive, they remained conscious of the cultural disparities that separated them from their fellow compatriots. As expressly stated by Sengstock, “... the Chaldeans are marginal to the Arab world in several ways. In the Middle East, the tendency to develop the broadened loyalties that accompany nationalism has come easier for Muslims than for Christians, not only because Muslims far outnumber Christians but also because of centuries of association between Arabic culture and the Muslim religion." (1982: 111)

In a similar vein, the spread of pan-Arabism in the postwar era, championed by the newly founded Ba'athist Party (1947), by no means precluded the dislocation of existing non-Arab/Muslim minority groups. Unsurprisingly, the new movement even provided for a secular Arab identity in which Iraqis of all stripes met as equal citizens. But the sentiment of security that prevailed over a number of decades, especially the feeling of making an integral part of the Iraqi national mosaic would soon cease to exist with the U.S. invasion of the country in 2003 and the defeat of the Ba'athist government. Indeed, the toppling of Saddam Hussein left Chaldeans and other Christian minorities without any protection and exposed them to the retaliation of certain Arab and Muslim groups who wanted to revenge their support of the much heated leader, let alone Islamic fundamentalists who simply refuted their right to exist on a "Muslim" land. (Mead, 2015)

The new geopolitical context dictated by what came to be known as the Gulf War instigated deep and full-scale shifts that shook the bedrock of Iraqi structures. It specifically placed the Chaldean minority under supplementary strains that seriously put at stake its resolve to safeguard and perpetuate its cultural heritage. In addition to survival strategies members the group deployed for self-protection in the midst of spreading sectarian vagaries, notably remaining invisible or seeking refuge in human rights protecting countries, they sought inclusion in the Iraqi reconstituted social fabric where they could claim a full-fledged minority status that guarantees their political and civic rights, and especially preserves their ethno-religious identity.

Arguably, presuming that Chaldeans enjoyed full protection against coercive attempt subjecting them to an Arab/Muslim identity would be inaccurate and, to certain degrees, historically unsubstantiated. Nevertheless, they have succeeded in maintaining a socio-cultural pattern of their own which they strongly articulated in the newly-drafted constitution (November 2005), namely Article 122 which "officialized" their autonomous status alongside other minority groups such as the Kurds, Assyrians, Turkomen, and other fragments of Iraqi society. (Hanish, 2010)

\subsection{Chaldeans after Relocation}

The shift from an Iraqi rhetoric to an American one did not change anything in the Chaldeans' resolve to eternalize their deeply cherished values and identity. In truth, while the new multicultural and multi-confessional context offered an invaluable opportunity for the Chaldean diaspora to preserve their heritage, it equally presented a dual challenge to a minority that is constantly called to strike the right balance between the desire to assimilate and the need to sustain its cultural distinctiveness, and at the same time demarcate itself from the Arab American and American Muslim stock, negatively stereotyped and collectively associated with terrorist networks.

Basically, refashioning their ethnic identity alongside American mainstream lines so as to fit as transplants in an entirely novel sociocultural context presupposed transcending the narrow bounds of the native village (Telkaif), especially crossing the boundaries of the ethnic group to reach out for the "Other." To this end, Chaldeans were not only called to 
be receptive to outside influence, but also to demonstrate some kind of ethnic openness and interaction, notably that they shared several common features with their new fellow citizens, including strong family ties, hard work, free enterprise, and strict moral and religious codes. The question, therefore, that comes to prominence is: How could Chaldeans adjust to their new environment and thrive in diversity without relinquishing some of their core patterns in favor of those of their adoptive homeland? They need first to reconstitute their cultural legacy, especially redefine their ethnic identity much beyond the loose conceptualization that tends to picture them in a static way, as pertinently stressed by cross-cultural psychologist Peter Weinreich who considers self-identity as a fluid process that takes diverse forms according to particular social contexts. (Weinreich \& Saunderson, 2003)

Few studies have been conducted to date to showcase the Chaldean group in what ethnic experts dubbed the "minority-majority dialectic." Well-known sociologist Will Herberg, for instance, suggests that while fully or partially adhering to American values and symbols, ethnic groups are obligated to self-identify with their ancestors, and have to articulate their cultural legacy in the most satisfactory way possible (1955: 257). Thus, in addition to promoting consensus and communality among group members, or what Greeley called a "primordial" sense (1971: 42), a self-perceived ethnic identity provides more than a sense of belonging, it, in the terms of Sengstock, "provides a sense of personal worth that gives individuals the confidence to deal with others outside as within the group." (1982: 151). Likewise, the little data available about Chaldeans suggest that while adamantly uncompromising on their oneness, Chaldeans are by no means ethnocentric people, incapable of interacting beyond the restricted confines of their community. (1982: 150)

In the same line of thought, a widely held assumption about assimilation maintains that to achieve a fairly high degree of immersion in the dominant culture, minority members are expected to exhibit adherence to what Gordon calls "external aspects of culture", likely to change rapidly (for instance, language, dress, and dietary customs), and "basic aspects of culture" which center around values and behavioral norms that persist over time (1964: 65-68). In this respect, Chaldean Americans appear to be flexible with regard to the first (except probably for the Aramaic dialect which they have resurrected in the United States and which they continue to use alongside the English and Arab languages), but staunchly unyielding on their core patterns, namely inter-group support and self-help, the omnipotent role of the Church in community life, and a noticeable propensity for endogamous marriages.

In sum, reaching out for individuals and groups outside the community, in other terms developing peripheral contacts based on trust and acceptance, has rarely been an outstanding feature of Chaldean Americans who, probably more than any other group, share a common obligation to preserve their heritage in its purest shape. Furthermore, specific instances of intergroup antagonisms have been reported and have frequently involved neighboring African-American members in the Detroit area who resent the way Chaldeans (whom they wrongly take for Arabs/Muslims) operate their liquor stores. They equally reject their closed business networks that contestably offer no possibility for recruitment outside the extended family, let alone the higher prices they practice in their poor areas. (Sengstock, 1982: 60).

Another facet of the Chaldean community is the general tendency, among its members, to downplay the role of education as a highly regarded American symbol and a way to self-betterment, and opt rather for educating their children in the strict culture of their ancestors. According to Sengstock, even though Chaldeans are a concrete embodiment of the American notions of the self-made man, self-reliance and hard work, they do not perceive education as a basic instrument to vehicle values of openness and peaceful coexistence, and public schools as civic and acculturating mills. (1982: 63)

Tackled from another perspective, the designation "ethnic identity" has been defined as "the sameness of a person or thing at all times in all circumstances; the condition or fact that a person or thing is itself and not something else." (Simpson \& Weiner, 1989: 60). Applied to Chaldean Americans, it demonstrates how group identity is often contingent upon the need to demarcate themselves from other groups, and emphasize their distinctive characteristics. In this respect, by distancing themselves from their Arab and Muslim peers, alas negatively associated with terrorism and anti-Americanism, they clearly exhibit a firm determination to cut irrevocably with a bitter past, especially with the modus operandi of the Arab and Muslim majority in the homeland. Thus, crossing the boundaries of their ethnic group in no way surmises sheer surrender of their core principles, as in the minds of many Americans, they remain closely associated with the Arab ancestry and faith.

Interestingly, repudiating their Arab and Islamic cultural background meant, for the Chaldean diaspora, fully assuming their "non-Arabness." One way to achieve this goal and thrive in the American multicultural context without being mingled with their Arab and Muslim neighbors, was to renounce to their Arabic sounding names in favor of more "American" sounding ones. Hence, Daoud became David, Wafa became Faith, Naim has been replaced with Norman, Karim with Karl, etc. (Sengstock, 1982: 76)

In a similar vein, setting up boundaries for the sake of preserving what Yuet Cheung dubbed "the psychological 
attachment to an ethnic group or heritage" (1993: 1216) entails giving shape to a self-perceived identity that still falls short of rallying the bulk of Chaldeans who continue to self-identify dissimilarly. As shown in Table 1 which clearly reflects the group's multifaceted character, a sizable number among community members prefer to identify as "Chaldeans," as the designation has come up to bear not only a national connotation, but also a linguistic, cultural, as well as religious one. Surprisingly, only six percent expressed preference for their "Telkeffee" name, a choice that utterly confirms their tendency to transcend the narrow contours of the village identity. In contrast, only 29 percent favor being designated by the following nationalistic epithets: Arab American, Christian Arab, or Iraqi Christian / Iraqi Chaldean. If the above figures reflect anything, they confirm a sweeping tendency, according to Sengstock, to cut indefinitely with their Arab/Muslim background. (1982: 113)

Regardless of the question of who is or is not a bona fide member of the community, articulation of the ethnic identity can also take a more official form when used to determine the demographic positioning of the group in the national count. Accordingly, to survive as a distinct minority in the new multiethnic setting, especially to resist extinction in a homogenizing context, Chaldeans need more than ever to unite under the identity of their ancestors, an identity which they appear resolute to safeguard and perpetuate. In effect, more than an issue of self-perception or ethnic pride, members of the Chaldean diaspora have to overcome the dual challenge of avoiding being lumped in the same category of their Arab peers with whom they share the same geographical area of origin, and simultaneously making sure not to be tabulated alongside Assyrians, which would simply imply disunion and further dispersion in exile.

The introduction, in the 1980 Census, of a new category related to ancestry which replaced the question of parents' place of birth that had been used since 1870, added to the confusion over group identity and further complicated the task of categorizing residents in light of their ethnic origin or descent, "roots", or heritage. More importantly, while based on historical information gathered through meetings with communities' leaders, the newly integrated open-ended question of "ancestry" often led to statistical inconsistencies and erroneous data. As a matter fact, Arab Americans, for instance, who are classified as "white," are currently lobbying the U.S. Census to create a Middle East and North Africa (MENA) category for the 2020 decennial count. They consider that being "pigeonholed" in the "white" category without being treated as such, bears a dual injustice of further marginalizing them, and at the same time preventing them from acquiring minority advantages, notably the socio-economic benefits they could derive from the local, state, and federal programs in terms of education, health, and equal employment opportunities. (Wiltz, 2014)

Within a much-reduced framework, and with the 2000 Census in prospect, the ancestry question reinforced the Chaldeans' resolve to demarcate themselves further from their Arab peers, and made it plain that they could never accept a nationalistic identity that is based upon the Arabic language. In the same vein, the rift over the new category snowballed into a real bone of contention between Chaldeans who chose to remain under a single ancestry code, and their Assyrian counterparts (concentrated in Turlock, California) who opted for a multi-ancestry designation that would comprise Assyrians, Chaldeans, and Syriacs as Semitic speakers of the Aramaic language. To Assyrian leaders, regardless of their denominational differences, the afore-mentioned groups not only originated from the same geographical area (Mesopotamia), but also shared a common linguistic and cultural heritage.

Table 1. Identification Preferred/Disliked by Members of Chaldean Community (1973)

\begin{tabular}{|c|c|c|c|c|}
\hline & & & Liked Best (\%) & Liked Least (\%) \\
\hline \multirow[t]{4}{*}{ A. } & Arabic Nationalist Names & Arab American & 9 & 15 \\
\hline & & Christian Arab & 4 & 2 \\
\hline & & Iraqi Christian or Iraqi Chaldean & 16 & 8 \\
\hline & Total Arabic & & 29 & 25 \\
\hline \multirow[t]{7}{*}{ B. } & Traditional Names & Telkeffee & 6 & 20 \\
\hline & & Chaldean & 40 & 4 \\
\hline & & Chaldean American & 9 & 2 \\
\hline & & Assyrian/Babylonian & 3 & 3 \\
\hline & $\begin{array}{l}\text { Total Traditional } \\
\text { Other Names or }\end{array}$ & & 58 & 29 \\
\hline & No Response & & 13 & 46 \\
\hline & Total & & 100 & 100 \\
\hline
\end{tabular}

Source: Sengstock, M. C. (1982). Chaldean Americans: Changing conceptions of ethnic identity, p. 113.

Eventually, even though their main concerns for qualifying as a separate group was rather motivated by a pronounced drive to preserve their Catholic faith with which they thoroughly identify, and despite a manifested disinterest in politics, Chaldean leaders consented ultimately to the multi-group classification, a decision which ostensibly made sense with regard to their reduced numbers. (Kulish, 2001)

\section{Consensus vs. Conflict}

Rarely addressed in the sociological literature that customarily depicts minority groups as ones in which consensus 
predominates, internal ethnic conflicts have often been a palpable reality that variably affects the diverse communities cohabiting in the American multiethnic context. What's more, pressure generally exerted on individual members to subordinate their personal interests to those of their group has on occasion given rise to internal frictions which, in some cases, grew into a real identity crisis. In such scheme of things, Chaldeans make no exception even if, compared with other groups, appear to exhibit broad consensus on basic elements of association that unite them.

Interestingly, to identify as an ethnic group necessitates more than a communality of historical and cultural patterns. It is first and foremost a question of self-perception, be it a feeling, an attitude, or a state of mind. Self-perception becomes, however, problematic when community members diverge on a single identity and, in the case of Chaldean Americans, cannot agree on whether to be labeled Chaldean, Telkeffee, Arab, or Iraqi. In the process, two subgroups developed within the diaspora: the Chaldean-oriented, identifiable among early immigrants and their offspring born and reared in the United States, and adherents of Arabic nationalism, identifiable among recent arrivals, mostly born in Baghdad (Iraq), highly educated, and known for their propensity to develop outside contacts. (Sengstock, 1982: 117)

Table 2. Preferred Identification Pattern by Selected Social Variables (1973)

\begin{tabular}{|c|c|c|c|c|c|}
\hline & & $\begin{array}{l}\text { Prefer Traditional } \\
\text { Identity }(\%)\end{array}$ & $\begin{array}{l}\text { Prefer Arab } \\
\text { Identity }(\%)\end{array}$ & $\begin{array}{c}\text { No Preference } \\
(\%)\end{array}$ & $(\mathrm{N}=)$ \\
\hline \multirow{2}{*}{ A. } & Age Under 40 & 56.1 & 31.6 & 12.2 & (57) \\
\hline & Over 40 & 60.5 & 25.6 & 13.9 & 43 \\
\hline \multirow[t]{5}{*}{ B. } & Immigrant Period & & & & \\
\hline & Pre-1961 & 70.4 & 18.5 & 11.1 & (27) \\
\hline & $1961-1965$ & 50.0 & 21.4 & 28.6 & (14) \\
\hline & $1966-1974$ & 43.6 & 48.7 & 7.7 & (39) \\
\hline & $\begin{array}{l}\text { Born N. America } \\
\text { (including Mexico) }\end{array}$ & 85.6 & - & 14.3 & (14) \\
\hline \multirow[t]{4}{*}{ C. } & Place of Origin & & & & \\
\hline & Village (Telkaif) & 60.0 & 25.0 & 15.0 & (40) \\
\hline & Urban (Baghdad) & 41.0 & 51.3 & 7.7 & (39) \\
\hline & Other Birth Place & (not calculated) & & & (21) \\
\hline \multirow[t]{6}{*}{ D. } & Church Attendance & & & & \\
\hline & At Least Monthly & & & & \\
\hline & Mother of God & 54.8 & 35.7 & 9.5 & $(42)$ \\
\hline & Sacred Heart & 40.0 & 40.0 & 20.0 & (25) \\
\hline & Other & & & & \\
\hline & (Primarily Latin rite) & 58.6 & 24.1 & 17.2 & (29) \\
\hline \multirow[t]{3}{*}{ E. } & Occupation & & & & \\
\hline & Ethnic Business & 55.6 & 26.7 & 17.8 & (45) \\
\hline & Outside Occupation & 59.3 & 31.5 & 9.3 & (54) \\
\hline \multirow[t]{8}{*}{ F. } & Education & & & & \\
\hline & 1. Amount & & & & \\
\hline & High school or less & 56.5 & 30.2 & 13.2 & (53) \\
\hline & Some college or more & 59.5 & 28.6 & 11.9 & (42) \\
\hline & 2. Place & & & & \\
\hline & Baghdad & 51.8 & 37.5 & 10.7 & $(56)$ \\
\hline & Telkaif (at least part) & 52.9 & 35.3 & 11.8 & (17) \\
\hline & U.S. and elsewhere & 79.2 & 4.2 & 16.7 & (24) \\
\hline \multirow[t]{9}{*}{ G. } & Outside Contact & & & & \\
\hline & $\begin{array}{l}\text { Organizational } \\
\text { Memberships }\end{array}$ & & & & \\
\hline & Chaldean only & 65.2 & 17.4 & 17.4 & (23) \\
\hline & Outside Organizations & 47.8 & 39.1 & 13.0 & (23) \\
\hline & Neither & 59.3 & 29.6 & 11.1 & (54) \\
\hline & 2. Closest Friend & & & & \\
\hline & Chaldean-relative & 48.7 & 41.0 & 10.3 & (39) \\
\hline & Chaldean-non-relative & 68.6 & 22.9 & 8.6 & (35) \\
\hline & Non-Chaldean & 56.5 & 17.4 & 26.1 & (23) \\
\hline
\end{tabular}

Source: Sengstock, M. C. (1982). Chaldean Americans: Changing Conceptions of Ethnic Identity, pp. 119-120.

In a fact-finding survey conducted by Sengstock in 1972-3, gathered data suggested even significant disparities between the above-mentioned trends, very likely to deepen with their diverging attitudes on the polarizing question of ethnic identity. As clearly demonstrated in Table 2, a large number among early immigrants (70.4 percent) and American born Chaldeans ( 85.6 percent) retained the traditional identification pattern, against only 43.6 percent of recent arrivals (1966 -1974). Meanwhile, only 18.5 percent of the old stock identified as Arabs, against 48.7 percent among new immigrants. In a similar vein, while age appeared to be a less significant factor in determining identification patterns in the Chaldean community, place of birth, in contrast, was relatively decisive in so far that half of the respondents born in Baghdad 
(51.3 percent) identified as Arabs, compared with only one-fourth ( 25 percent) who were born in the Iraqi village of Telkaif. What's more, Church attendance was also decisive in so far that adherence to traditional identity was remarkably significant among Chaldeans who attended the oldest Chaldean parish (Mother of God) on a regular basis (54.8 percent). When it lastly came to occupation, minor differences in the identification patterns were noticed between Chaldeans involved in the ethnic business of groceries and those who held jobs outside the community, with respectively 55.6 percent of the former who preferred the traditional identity and 59.3 percent among the latter.

A number of conclusions can be drawn from the above data:

First, it would be unfounded and, to certain degrees, unwise to rush to judgment and consider that the Chaldean group is undergoing an identity crisis. Likewise, it would be inaccurate to portray the community as one that is irreversibly divided over the question of ethnic identification, and with no solution in sight. Arguably, while disagreements over the issue have incontestably widened the gap between traditionalists within the group and their Arab-oriented detractors, envisaging a total split between the two subgroups appears unthinkable. According to Sengstock, identification with the Chaldean ancestral heritage, especially traditional ties of family, religion, and language, remains strong across the whole community. (1982: 126)

Second, despite newly emerging socioeconomic barriers separating the two components of the group (with the early immigrants now rather well-off and residing in the luxurious suburbs of the Detroit area, and recent arrivals clustered in the modest neighborhoods of the central city), a sizable number still think of themselves as Chaldeans or Chaldean Americans, and continue to speak the Aramaic dialect among themselves. (1982:126)

Lastly, while they continue to exchange accusations, with the old stock complaining the new arrivals have abandoned the "real Chaldean way," and the new stock viewing early immigrants as peasants arriving from Telkaif, "a crummy little town," terrain for consensus remains quite likely in light of the community's determination to preserve the Chaldean tradition in its purest state and pass it over to future generations as their ancestors managed to do it over the ages. (Sengstock, 1982: 132)

\section{Concluding Remarks}

In conclusion, one may presume that despite the fact that they have not been the focus of much of the ethnic literature, Chaldean Americans represent an interesting case study. Probably more than any other group, they have demonstrated sufficient confidence to surmount challenges and at times even survive erasure. In essence, Chaldeans succeeded in perpetuating an ancestral heritage which they have preserved in its original configuration. What's more, bouncing from one world to another, namely from a majoritarian Arab and Muslim setting to a multicultural and multi-faith context did not and in any way reduce their resolve to keep the tradition intact, while adjusting to their new environment.

However, keeping abreast of changing times, especially maintaining their distinctive features requires not only group cohesion and unity, but also an all-encompassing consensus regarding the question of identity. The development of two competing trends within the Chaldean community, advocating dissenting and, to certain extents, polarizing views regarding this sensitive issue, but also the way group members interact outside the ethnic enclave, comes here as an alerting signal against assumptive disunion and disintegration.

Seen from another perspective, while threatening to non-Western cultures, the use of digital technology and interactive media in general can be used by ethnic minorities facing homogenization in their respective societies. To this regard, and to survive the digital age, the Chaldean microcosm is probably called to derive the utmost benefit from the new means of communication put at its disposal by the technological revolution to promote its cultural heritage and especially safeguard the essence of its identity.

Overall, whether they define themselves as Chaldean or Arab, one misses completely the point if one pictures them as a monolith, immune to change an evolution. Available literature indicates, however, that substantial mutation has profoundly altered the internal structure of the Chaldean community. To take but a few illustrative examples, even though still high by American standards, the number of extended family households within the Chaldean group has decreased exponentially, coinciding with the arrival of new immigrants. Likewise, still highly frowned upon, exogamy is now a practical reality among Chaldeans, namely the recent stock. In the same vein, strictly observed until recently, the intra-family business arrangements have decreased considerably with more and more Chaldeans opting for an occupation outside the community. By contrast, Church and family still exert a great deal of influence over the lives of the diaspora members regardless of their socioeconomic profile.

\section{References}

Anonymous (1982). Chaldean Americans: Changing conceptions of ethnic identity. New York: Center for Migration Studies of New York, Inc. 
Aswad (Ed.), Arabic-speaking communities in American cities. New York: Center for Migration Studies and Association of Arab-American University Graduates.

Bell, D. (1975). Ethnicity and social change. In N. Glazer \& D. P. Moynihan, (Eds.), Ethnicity: Theory and practice (pp. 174n), Cambridge: Harvard University Press.

Cheung, Y. W. (1993). Approaches to ethnicity: Cleaning roadblocks in the study of ethnicity and substance abuse. International Journal of Addictions, 28(12), 1209-1226. https://doi.org/10.3109/10826089309062185

Farsoun, S. K. (1970). Family structure and society in modern Lebanon. In L. E. Sweet (Ed.), Peoples and cultures of the Middle East (Vol. II).

Gleason, P. (1996). Identifying identity: A semantic history. In W. Sollars (1996), Theories of ethnicity: A classical reader (pp. 460-487). New York: New York University Press. https://doi.org/10.1007/978-1-349-24984-8_24

Gordon, M. (1964). Assimilation in American life. New York: Oxford University Press.

Hanish, S. (16 March 2010). The Chaldean Assyrian Syriac people of Iraq: An ethnic identity problem. Digest of Middle East Studies. Retrieved from https://onlinelibrary.wiley.com/doi/pdf/10.1111/j.1949-3606.2008.tb00145.x

Herberg, W. (1955). Protestant, Catholic, Jew. New York: Doubleday.

Hourani, A. H. (1946). Syria and Lebanon. London: Oxford University Press.

Kamoo, R. (1999). Ancient and Modern Chaldean History. Lanham, Maryland: Scarecrow Press.

Kulish, N. (12 March 2001). Wrong Pigeonhole? Chaldeans, Assyrians are vexed with census --- Groups go way back together, but neither of them wants to share 'ancestry' billing. The Wall Street Journal. Retrieved from https://searchproquest.com/abiocomplete/docview/398809109/9B87A0D369BD414APQ/4?accountid+142908

Mead, W. R. (15 May 2015). The plight of the Middle East's Christians: Ancient communities in Syria and Iraq are in mortal peril. Can the West find a way to preserve the Christian presence in the Middle East—and save off a "clash of civilizations'? Wall Street Journal. Retrieved from https://search.proquest.com/abicomplete/docview/1680986264/5487447C71C241D1PQ/27?accountid=142908

Norris, K. (14 May 2006). From Mesopotamia to Metro Detroit: Transplanted Iraqi Christians move forward with a museum celebrating Chaldean culture. Detroit Free Press. Retrieved from https://searchproquest.com/abicomplete/docview/465525149/fulltext/9B87A0D369BD414APQ/7?accountid=1429 08

Phinney, J. (2003). Ethnic identity and acculturation. In K. Chun, P. B. Organista, \& G. Marin (Eds.), Acculturation: Advances in theory, measurement, and applied research (pp. 63-81). Washington, DC: American Psychological Association. https://doi.org/10.1037/10472-006

Prothro, E. T., \& Diab, L. N. (1974). Changing family patterns in the Arab east. Beirut, Lebanon: American University of Beirut.

Przybysz, A. M. (2012). Chaldean Americans. In S. Loue \& M. Sajatovic (Eds.), Encyclopedia of immigrant health. https://doi.org/10.1007/978-1-4419-5659-0_125

Raban, R. (1967). Chaldean rite. New Catholic Encyclopedia (pp. 3:427-430). New York: McGraw-Hill.

Sengstock, M. C. (1974). Iraqi-Christians in Detroit: An analysis of an ethnic occupation. In B. C.

Shathaya, G. H. (1999). Who are the Chaldeans? Chaldeans Online. Retrieved from http://www.chaldeansonline.org/chald.html

Simpson, J. A., \& Weiner, E. S. (1989). The Oxford English dictionary (2 $2^{\text {nd }}$ ed., Vol. VII). Clarendon Press.

Weinreich, P. (1986). The operationalization of identity theory in racial and ethnic relations. In J. Rex and D. Mason (Eds.), Theories of race and ethnic relations (pp. 299-320). England: Cambridge University Press. https://doi.org/10.1017/CBO9780511557828.016

Weinreich, P., \& Saunderson, W. (Eds.). (2003). Analyzing identity: Cross-cultural, societal and clinical contexts. New York: Routledge.

Wiltz, T. (13 Aug. 2014). Lobbying for a 'MENA' category on U.S. census. USA Today. Retrieved from https://www.usatoday.com/story/new/nation/2014/08/13/stateline-census-mena-africa-mideast/13999239

\section{Copyrights}

Copyright for this article is retained by the author(s), with first publication rights granted to the journal.

This is an open-access article distributed under the terms and conditions of the Creative Commons Attribution license which permits unrestricted use, distribution, and reproduction in any medium, provided the original work is properly cited. 